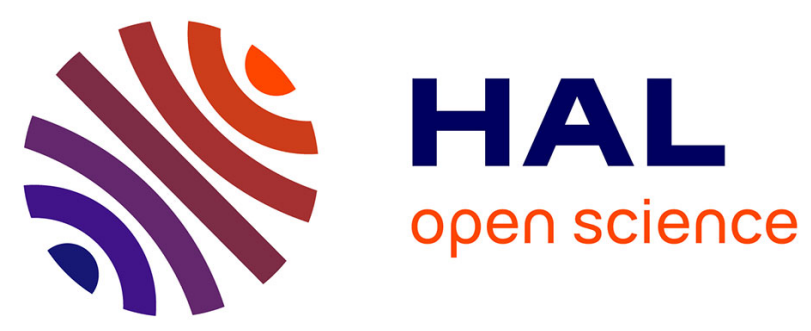

\title{
To What Extent Does Text Simplification Entail a More Optimized Comprehension in Human-Oriented CNLs?
}

\author{
Nataly Jahchan, Anne Condamines, Emmanuelle Cannesson
}

\section{To cite this version:}

Nataly Jahchan, Anne Condamines, Emmanuelle Cannesson. To What Extent Does Text Simplification Entail a More Optimized Comprehension in Human-Oriented CNLs?. Controlled Natural Language, Jun 2016, Aberdeen, United Kingdom. pp.69 - 80, 10.1007/978-3-319-41498-0_7 . halshs01379559

\section{HAL Id: halshs-01379559 \\ https://shs.hal.science/halshs-01379559}

Submitted on 11 Oct 2016

HAL is a multi-disciplinary open access archive for the deposit and dissemination of scientific research documents, whether they are published or not. The documents may come from teaching and research institutions in France or abroad, or from public or private research centers.
L'archive ouverte pluridisciplinaire HAL, est destinée au dépôt et à la diffusion de documents scientifiques de niveau recherche, publiés ou non, émanant des établissements d'enseignement et de recherche français ou étrangers, des laboratoires publics ou privés. 


\title{
To What Extent Does Text Simplification Entail a More Optimized Comprehension in Human-oriented CNLs?
}

\author{
Nataly Jahchan ${ }^{1,2}$, Anne Condamines ${ }^{1}$, Emmanuelle Cannesson ${ }^{2}$ \\ ${ }^{1}$ CLLE, University of Toulouse, CNRS \\ ${ }^{2}$ Airbus Operations SAS \\ \{nataly.jahchan, emmanuelle.cannesson\}@airbus.com, \\ anne.condaminesQuniv-tlse2.fr
}

\begin{abstract}
The main goal of the current study is to develop a new cockpit controlled language for future Airbus aircraft by using psycholinguistic testing to optimize pilot comprehension. Pilots are aided by cockpit messages in order to deal with different situations during aircraft operations. The current controlled languages used on the Airbus aircraft have been carefully constructed to avoid ambiguity, inaccuracy, inconsistency, and inadequacy (Spaggiari, Beaujard, Cannesson (2003)) in order to ensure the safety of the navigation, operational needs, and the adaptability of the human-computer interaction to different situations in the cockpit. However, this controlled language has several limitations, mostly due to small screen sizes (limited number of words and sentences) and is highly codified (non-conforming to natural language syntax, color-coded and so on) so that it requires prior pilot training in order to achieve fluency. As future cockpit design is under construction, we might be looking at a different flexibility margin. Our experimentation plan is to go against the tide of common CNL (Controlled Natural Language) construction, in the sense that we will not be taking natural language and simplifying it, but rather taking a highly controlled codified language (therefore theoretically most simple) and "complexifying" it (bring it closer to natural language: theoretically most complex) in order to make it more accessible, and limit prior training needs.
\end{abstract}

Keywords. Human-oriented CNL, controlled language, Airbus cockpit alarms, Human Factors, psycholinguistics, text comprehension, sentence superiority effect, comprehension optimization

\section{Introduction}

Going back to the origins of controlled languages, we would find that the main goal of the first CNLs was to facilitate communication among humans - such is the case with BASIC English, created by Charles Ogden in 1930.

Readability research and controlled language production (BASIC English, PLAIN English, AECMA SE, etc.) have constantly been criticized for lack of empirical 
research that justify their rules and existence. Rudolf Flesch in his article "How Basic is Basic English?"1 claims that Basic English "is neither basic nor English" and starts off with an example "If I were Mr. Churchill, I would not like being reduced to calling Hitler "a very bad man" or a bomber "an air plane sending down hollow balls full of substance with a tendency to go off with a loud noise", in reference to Basic English's arbitrarily selected 850 word vocabulary. He criticizes Ogden for "deliberately avoid[ing] the scientific approach and not [being] lucky enough to find the key to simplicity by accident".

With time, the very nature of our modern day communication has pushed researchers to find different usages (i.e. other than CNLs for facilitating communication, mutual comprehension and ease of use) for controlled/simplified/processable/etc. languages such as automatic translation or formal notations in different domains (Industry, Academia, Government, etc.). See Kuhn [7] for a complete survey of the available CNLs and their usage.

AECMA SE, more recently known as ASD-STE (Aerospace and Defense Simplified Technical English), one of the most complete, widely used human-oriented controlled languages (a language that has survived the test of time and is still used in the Aircraft maintenance domain, and across different aircraft manufacturers) was also accused of harboring anecdotal, intuition-based evidence to justify its many rules of use. The lack of scientific evidence was jarring at the time of AECMA SE's adoption in aircraft maintenance, specifically in the aeronautic domain where the consequences of inaccurate comprehension could lead to potentially dangerous situations. According to Hinson (1988) $)^{2}$, “AECMA's Simplified English claims to be founded on readability research. It would be interesting to establish the nature, validity, and appropriateness of the research used. It would also be helpful to know of any research carried out on Simplified English manuals in use."

To this effect, a wave of research studies in the mid-90's (Shubert et al.(1995) [9], Chervak et al. (1996)[2], Chervak (1996)[1], Eckert (1997)[4], Stewart (1998)[12]) was launched to acquire the much needed empirical evidence that AECMA SE lacked. These studies will be of great interest in our current study. The experiments conducted and relevant results will be elucidated in section 4.2.

\section{Context}

For the purposes of our research, we will only be interested in human-oriented CNLs, that is to say CNLs whose main goal is to enhance/improve/optimize human comprehension in a given corpus. By improving comprehension we are targeting three main aspects: faster comprehension, more accurate comprehension, and limited training needs.

This paper is part of the author's PhD research launched by the Human Factors department of Airbus Operations SAS in Toulouse, France in collaboration with CLLE

R. Flesch, How Basic Is Basic English?, Harper's Magazine, 188:1126 (1944:Mar.) p.339.

2 D. E. Hinson, Simplified English-Is It Really Simple? WE 33-36, 1988. 
(Cognition, Langues, Langage, Ergonomie) laboratory of Toulouse 2 University. Based in Toulouse, an aerospace hub, CLLE laboratory has cultivated a knowledge base in the CNL domain and specialized corpora related to space and aviation (see Warnier and Condamines (CNL, 2014) $)^{3}$, Lopez and Condamines (2013) ${ }^{4}$ ). As such, the main goal of the current study is to develop a new cockpit controlled language for future Airbus aircraft by using psycholinguistic testing to optimize pilot comprehension. Pilots are aided by cockpit messages in order to deal with different situations during aircraft operations. The current controlled languages used on the aircraft have been carefully constructed to avoid ambiguity, inaccuracy, inconsistency, and inadequacy (Spaggiari, Beaujard, Cannesson $(2003)^{5}$ ) in order to ensure the safety of the navigation, operational needs, and the adaptability of the human-computer interaction to different situations in the cockpit. However, this controlled language has several limitations, mostly due to small screen sizes (limited number of words and sentences) and is highly codified (non-conforming to natural language syntax, highly abbreviated, typographically variable, color-coded and so on (cf. figure 1)) so that it requires prior pilot training in order to achieve fluency. As future cockpit design is under construction, we might be looking at a different flexibility margin. Figure 1 is an example of different messages found at different locations in one of the corpora at hand (this is not an exact replica of an alarm).

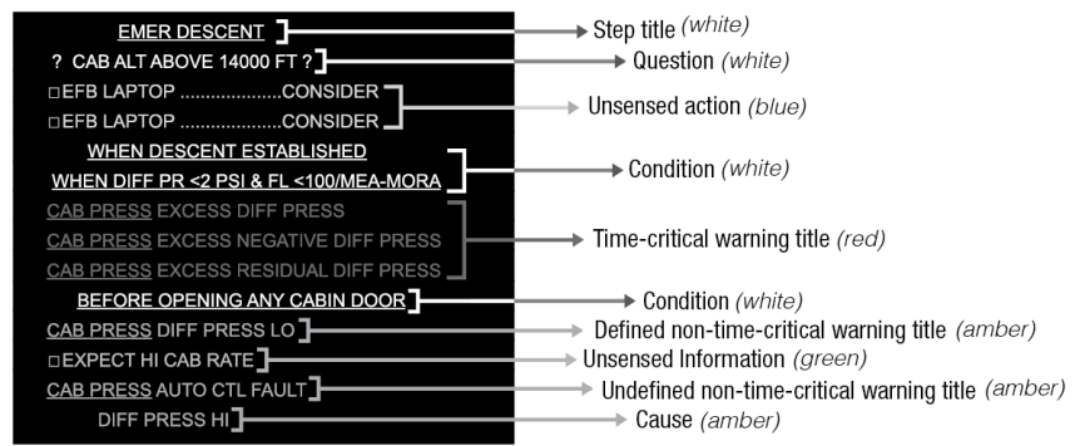

Figure 1 Example of different messages in cockpit corpus

\section{$3 \quad$ Aim}

It has been broadly acclaimed by many scholars that natural language breeds ambiguity and linguistic chaos. In a sense, that statement is true since natural language has

3 Condamines, A. Warnier, M. 2014. Linguistic Analysis of Requirements of a Space Project and their Conformity with the Recommendations Proposed by a Controlled Natural Language.

4 S. Lopez, A. Condamines, A. Josselin-Leray, M. O’Donoghue, R. Salmon, 2013 : "Linguistic Analysis of English Phraseology and plain Language in Air-Ground Communication" . Journal of Air Transport Studies, Volume 4, Issue 1. p. 44-60.

5 Spaggiari, L, Beaujard, F, Cannesson, E. 2003. A Controlled Language at Airbus. In Proceedings of EAMT-CLAW03, p. 151-159, Dublin. 
theoretically infinite possibilities of expression and interpretation, but in another sense, natural language is the most common and constant tool in our cognitive process of everyday life. Syntactic constructions, morphological derivations, way of thought, all come naturally in the way we acquire them at an early age; or the way non-native speakers of a given language, let's say English, first learn the language at its most basic form and construction: naturally, without any control.

We therefore argue that the exposure to natural language for both native and nonnative speakers influences the way people will understand a certain text and respond to it efficiently. In other words, a non-ambiguous text written in a natural language construction would, in our opinion, be more easily understood than a coded, controlled, and syntactically non-conforming to natural language CL. This is due to speakers being more exposed to a certain natural language and its constructions in their usage of this language in their everyday life. Or so we hypothesize. We will endeavor in this study to find empirical proof to substantiate or infirm this argument.

The idea is not to eliminate controlled language altogether. For then, without rules, common linguistic ambiguities would be very easy to come by. The real question is: what is the right balance? Researches have been quite adamant that "simplification" was the right way to proceed to achieve better comprehension. Readability, textcomplexity, text-cohesion research have all focused on the process of simplification/controllability/structuration (Dubay (2004)[3], Temnikova (2012)[14], McNamara et al.(2010)[8], Van Oosten et al.(2010)[15], etc.). According to Van Oosten et al. (2010)[15], "the concept of readability has been defined in a wide variety of ways, typically dependent on the author's intentions. For instance, Staphorsius (1994) defines readability of a text as the reading proficiency that is needed for text comprehension. The author's intention of designing a formula to determine the suitability of reading material given a certain reading proficiency is not without its influence in that definition. McLaughlin (1974), the author of the influential SMOG formula, on the other hand, defines readability as the characteristic of a text that makes readers willing to read on." Or according to DuBay's 2004 definition "what makes texts easier to read than others". " In our case, readability is not about ease of reading, or reading proficiency or the characteristics that make readers willing to carry on reading. Readability in our sense is about usability of the text. What are the inherent qualities of a sentence that make it comprehensible? By comprehension, we mean that the information we want to transmit has been fully understood, the consequences of which should be the correct reaction to the information and the writer's intended meaning in the most optimal manner (fast and accurate comprehension and reaction).

In some CLs, simplification reduced the sentential elements to the basic essentials, and diminished the scope and complexity to the detriment of information loss. The following is an example of PLAIN English CL (controlled languages) taken from their website ${ }^{6}$ :

A. High-quality learning environments are a necessary precondition for facilitation and enhancement of the on-going learning process.

\footnotetext{
${ }^{6} \mathrm{http}: / /$ www.plainenglish.co.uk/
} 


\section{B. Children need good schools if they are to learn properly.}

According to the Plain English approach, these two sentences are synonymous, with sentence A being more difficult than sentence B. While that might very well be the case, sentence B does not say everything sentence A intends to say. The semantic field has been highly restricted. For instance, "learning environments" are not strictly limited to "schools", and not universities or home-schooling, tutoring etc. "Facilitation and enhancement" is not accurately summarized by "learning properly". The idea of an "on-going process" has been completely eliminated. In our opinion, those two sentences are in very little ways synonymous. Simplification has led to a substantial change/reduction of meaning that unless it specifically intended to do so, has failed to accurately "simplify". In other cases, making information more explicit and redundant caused the readers to lose what could be otherwise valuable time (Shubert et al.(1995) [9], Chervak et al. (1996)[2], Chervak (1996)[1], Eckert (1997)[4], Stewart (1998)[12]).

Codifying and abridging languages, controlling and simplifying, whether by using syntactic or other forms of ellipses could make a language difficult to assess for a lay speaker of a given language. That is to say, a codified language might require prior training and possibly more effort on the end user regarding direct and easy comprehension; a process that might well be exacerbated in situations of stress or danger. Therefore, the usefulness and usability of an acquired (in the sense of requiring prior learning) controlled language must be put to the test and undergo psycholinguistic scrutiny.

Our experimentation plan is to go against the tide of common CNL (Controlled Natural Language) construction, in the sense that we will not be taking natural language and simplifying it, but rather taking a highly controlled codified language (therefore theoretically most simple) and "complexifying" it (bring it closer to natural language: theoretically most complex) in order to make it more accessible. In other words, we want to bring it back to a more natural state: give it a more natural language structure, syntactically and otherwise. Therefore, our approach to simplification might not be the same as current CNL tendencies, in the sense that we are going backwards, towards natural language, while making sure not to fall in the trap of ambiguity.

We will go from a codified corpus to a more natural one, by using research that has been done on readability and complexity and test, bit by bit, how we can add sentential elements that would make the language closer to natural language structure of English. Our hypothesis is that by doing this we are making the language more clear because native and non-native end users are more exposed to the natural language and would not need prior training and learning to understand how to use it. At the same time by adding a sentence structure we would be limiting the different possible interpretations, therefore avoiding, as much as possible, elliptical ambiguities. This general thought has led us to delve into the different times research has empirically proven that controlling a language actually improved global human comprehension. And more than that, how much control was needed to actually achieve better comprehension, and what are the limits that could potentially render this control or oversimplification unsatisfactory/counter-productive? 


\section{State of the Art}

\subsection{Simpson and Hart}

Carol Simpson (1976)[10] studied the effects of linguistic redundancy on pilot's comprehension of synthesized speech (a study done for Human Factors research in aviation in a psycholinguistics context in NASA's Ames Research Center). She showed that by taking the time to form clear unambiguous sentences using the same original keywords, the message was detected more accurately and pilot's reaction times was faster. For instance, the message "fuel low" was inserted in a sentence in the same order "The fuel pressure is low" and "gear down" was inserted in "The landing gear is down". The same goes for "Autopilot disengaged" and "The autopilot is disengaged". Response times to sentences were approximately 1 second shorter than response times to two-word messages. The results take into account the duration of the messages. That is to say, even though the duration of the stimuli containing the keywords in sentences was longer, the reaction times in total were still faster in the case of keywords in sentences than in the case of simple keyword messages. The experiment also showed that key words in sentences were approximately 20 percent more intelligible than key words presented alone.

Moreover, sentence-length messages appeared to require less attention to comprehend than two-word messages (Sandra Hart, (1976)[5], concurrent study for NASA).

Cockpit alarms have a tendency to be presented in the form of short keyword messages rather than in the form of long sentences. Brevity is usually preferred because of the small window of time that the pilots have to react in time-critical situations. Therefore, the obvious way to economize on the time of stimuli presentation was to make the messages as short, precise, and non-ambiguous as possible so as to keep only the relevant information, and eliminate redundancy provided by a sentence structure, i.e. the suppression of syntactic sentential elements.

It was concluded in Simpson's research that the syntactic and semantic constraints provided by a sentence frame (which adds redundancy and explicitness) reduced the possible interpretations of keyword alerts. Furthermore, the pilot participants mentioned that "the longer pattern of the sentence with extra words between the critical ones gives you more time to understand the words" and in their case react faster to the alert. While these results are based on aural alerts, one could hypothesize that the same argument would work on written alerts.

Simpson's[10] and Hart's[5] concurrent studies offered the necessary background to start "de-codifying" our corpus by going towards natural language sentential structure. Contrary to the other human-oriented CLs' evaluations (Shubert et al. (1995) [9], Chervak et al. (1996)[2], Chervak (1996)[1], Eckert (1997)[4], Stewart (1998)[12], Temnikova 2012[14]), Simpson's study results showed that certain language structures (non-simplified natural language structures) actually decreased response time, which is a factor that is particularly of interest to us for optimizing comprehension. Additionally, to the best of our knowledge, it is one of the only experiments that tested accuracy of comprehension and time in short injunctive sequential messages as opposed to long chunks of text (Kiwan 2000[6], McNamara (2010)[8], etc.). 


\subsection{AECMA SE Evaluations}

We will now summarize the research experiments done on AECMA SE (Shubert et al.(1995) [9], Chervak et al. (1996)[2], Chervak (1996)[1], Eckert (1997)[4], Stewart (1998)[12]) which were done to substantiate SE's efficiency. These studies are important to us mainly because by questioning the extent of efficiency of controlled languages, we also question, to a certain extent, the legitimacy of controlling/(over)simplifying a natural language.

The researchers were interested in testing the effects of SE on comprehension, location of information on maintenance work cards and response time. They compared pre-SE work cards and their SE version. The experiment designs and dependent variables differed between those 5 experiments: both native and non-native speaker participants or exclusively non-natives, in an English speaking country or not, using technicians or students, using easy vs. difficult work cards, using reading comprehension for testing or actual performance of maintenance, testing for subjects' reading comprehension and level of English or not, testing or not the work cards' text complexity using Flesch-Kincaid readability tests ${ }^{7}$. Some results show that while SE appeared to be significantly better for comprehension on the whole, it also came short of significance in several different conditions. As seen in the comparative table (Figure 2), Shubert et al.[9] and Chervak et al.[2] are the only two studies that showed general SE superiority significantly. In Chervak[1], Eckert[4], and Stewart's[12] studies there were no significant results to substantiate SE superiority over non-SE versions. Furthermore, in Chervak et al.[2] and Shubert et al.[9] (the only experiments showing general SE significance) there was a significant interaction of comprehension of SE and non-SE by document type: The easy work cards (ones that described short and easy procedures as opposed to long and difficult ones) did not show any comprehension significance for SE, and only the hard ones did. Therefore, content is not significantly more comprehensible or easy to locate for the subjects working with the shorter easier procedure. Chervak et al.[2] showed that only certain work card types showed significant SE superiority over non-SE, which suggests that SE superiority, is document specific.

Finally, none of the experiments showed that SE significantly improved time. Shubert et al. even noted that in the easier work cards the subjects reading SE documents required more time to respond. Stewart also notes that participants in the SE condition needed to have a higher mean English-reading ability to obtain a mean task card similar to non-SE condition.

All of these studies concluded that while the superiority of SE seemed to be very document and condition specific, it did not adversely affect comprehension in the other conditions. Therefore, Chervak et al.[2] concluded that SE was suitable for use especially where it is needed most: in hard and long work cards and for non-native speakers. However, most interestingly Eckert[4] and Stewart[12] who only tested non-native speakers did not find any SE significance. Temnikova's[14] experiment is

7 Readability tests designed to indicate how difficult a reading passage in English is to comprehend. They rely on measuring word length and sentence length to provide a grade level of the text or a reading ease level. 
different from the other experiments since it was done 15 years later, and was testing a different CL: Controlled Language for Crisis Management (CLCM). It is relevant here because, like the previously mentioned 5 studies, it also tests a human-oriented CL psycholinguistically in a behavioral experimental protocol. Results showed that there was no statistically significant global superiority of the simplified CLCM over the "complex" natural language. It was significant in certain sets of text (again document-specific) and it did not show any significance with regards to response time. All of these results are summarized in Figure 2.

\begin{tabular}{|c|c|c|c|c|c|c|}
\hline Author/year & $\begin{array}{l}\text { Shubert et al. } \\
1995\end{array}$ & $\begin{array}{l}\text { Chervak et al. } \\
1996\end{array}$ & Chervak 1996 & Eckert 1997 & Stewart 1998 & $\begin{array}{l}\text { Temnikova } \\
2012\end{array}$ \\
\hline $\begin{array}{l}\text { Native and non- } \\
\text { native }\end{array}$ & Both & Both & Native & Non-native & Non-native & Both \\
\hline $\begin{array}{l}\text { Participants: } \\
\text { natives }\end{array}$ & 90 natives & 157 natives & 18 natives & 0 natives & 0 natives & 22 natives \\
\hline $\begin{array}{l}\text { Participants: } \\
\text { Non-natives }\end{array}$ & 31 non-natives & 18 non-natives & 0 non-natives & 148 non-natives & $\begin{array}{l}41 \text { non-natives } \\
\text { ( } 21 \text { different } \\
\text { countries) }\end{array}$ & 83 non-natives \\
\hline Profession & $\begin{array}{l}\text { Engineering } \\
\text { students }\end{array}$ & AMT's & $\begin{array}{l}9 \text { maintenance } \\
\text { students and } 9 \\
\text { experienced } \\
\text { mechanics }\end{array}$ & $\begin{array}{l}\text { Aviation } \\
\text { maintenance } \\
\text { students }\end{array}$ & $\begin{array}{l}\text { Electronics } \\
\text { technician } \\
\text { students }\end{array}$ & $\begin{array}{l}\text { All walks of } \\
\text { life(because not } \\
\text { testing SE, but } \\
\text { CLCM) }\end{array}$ \\
\hline Country & $\begin{array}{l}\text { English } \\
\text { speaking }\end{array}$ & $\begin{array}{l}\text { English } \\
\text { speaking }\end{array}$ & $\begin{array}{l}\text { English } \\
\text { speaking }\end{array}$ & $\begin{array}{l}\text { Non-English } \\
\text { speaking } \\
\text { (Mexico) }\end{array}$ & English speaking & $\begin{array}{l}\text { N/A (Online } \\
\text { experiment) }\end{array}$ \\
\hline Procedure & $\begin{array}{l}\text { Reading } \\
\text { comprehension, } \\
\text { between } \\
\text { subject }\end{array}$ & $\begin{array}{l}\text { Reading } \\
\text { comprehension, } \\
\text { between } \\
\text { subject }\end{array}$ & $\begin{array}{l}\text { Performing } \\
\text { maintenance, } \\
\text { between } \\
\text { subject }\end{array}$ & $\begin{array}{l}\text { Reading } \\
\text { comprehension, } \\
\text { between } \\
\text { subject }\end{array}$ & $\begin{array}{l}\text { Reading } \\
\text { comprehension, } \\
\text { between } \\
\text { subject }\end{array}$ & $\begin{array}{l}\text { Reading } \\
\text { comprehension, } \\
\text { between } \\
\text { subject }\end{array}$ \\
\hline $\begin{array}{l}\text { Tested for } \\
\text { English } \\
\text { comprehension }\end{array}$ & No & $\begin{array}{l}\text { Yes (but not } \\
\text { specifically for } \\
\text { non-natives) }\end{array}$ & No & Yes & Yes & $\begin{array}{l}\text { No (only self- } \\
\text { evaluation and } \\
\text { not used in } \\
\text { analysis) }\end{array}$ \\
\hline $\begin{array}{l}\text { General SE } \\
\text { Significance: } \\
\text { doc type }\end{array}$ & Yes & Yes & $\begin{array}{l}\text { No (means } \\
\text { followed trend) }\end{array}$ & $\begin{array}{l}\text { No (means } \\
\text { followed trend) }\end{array}$ & $\begin{array}{l}\text { No (means } \\
\text { followed trend)* }\end{array}$ & $\begin{array}{l}\text { No (means } \\
\text { followed trend) }\end{array}$ \\
\hline $\begin{array}{l}\text { Significance SE } \\
\text { comprehension: } \\
\text { easy }\end{array}$ & No & No & N/A & N/A & $\begin{array}{l}\text { N/A (only } 1 \\
\text { workcard) }\end{array}$ & $\mathrm{N} / \mathrm{A}$ \\
\hline $\begin{array}{l}\text { Significance SE } \\
\text { comprehension: } \\
\text { difficult }\end{array}$ & Yes & Yes & N/A & N/A & $\begin{array}{l}\text { N/A (only } 1 \\
\text { workcard) }\end{array}$ & N/A \\
\hline $\begin{array}{l}\text { Significance: } \\
\text { time/SE }\end{array}$ & $\mathrm{No}^{* *}$ & $\begin{array}{l}\text { No (will not } \\
\text { adversely } \\
\text { affect) }\end{array}$ & No & N/A & No & No \\
\hline $\begin{array}{l}\text { Significance: } \\
\text { time/native } \\
\text { speaker }\end{array}$ & N/A & Yes (normal) & N/A & N/A & No & N/A \\
\hline $\begin{array}{l}\text { Significance type } \\
\text { of workcards }\end{array}$ & $\begin{array}{l}\text { N/A (only } \\
\text { easy/difficult } \\
\text { was tested) }\end{array}$ & $\begin{array}{l}\text { Yes (only } \\
\text { certain } \\
\text { workcards) }\end{array}$ & N/A & N/A & N/A & $\begin{array}{l}\text { Yes (only certain } \\
\text { sets of text) }\end{array}$ \\
\hline
\end{tabular}

Figure 2 Comparative table summarizing most relevant results of different CL evaluations

The results of these experiments are relevant to our study for two main reasons: 1We are interested in time optimization and these AECMA SE and CLCM evaluations show that simplifying a language does not necessarily economize time and 2- because our corpus is made of short relatively uncomplicated sequential procedures and these results do not show CL superiority when it comes to easy procedures. 
These last results and Simpson and Hart's research has led us to give a more concrete form to our hypothesis, that native language syntactic structure on a sentential level would help us optimize comprehension.

\subsection{Sentence Superiority Effect}

Another interesting line of research in cognitive psychology and neuro-linguistics that is relevant to our study, deals with the sentence superiority/context effect. This effect asserts that sentences are easier to memorize/process than word strings. Just as letters are more easily read in words, words are more easily read in sentences. According to Simpson et al. (1989) [11], context facilitates the identification of lexical candidates. Therefore, this offers an additional point of view to back our argument of wanting to insert non-conforming-to-natural-syntax keywords of our corpus in sentences.

\section{Approach}

In our experiment, we will be testing comprehension of the corpus' acquired sequences (in the sense of them requiring prior user training) based on a mapping of categorically different types of information (action, advice, information, etc.) versus comprehension of sequences inserted in a grammatical close-to-natural-language sentence (not requiring prior training). In English, the most dominant natural syntactic construction would be in an SVO (subject-verb-object) format. Furthermore, SVO structure is the most common order by number of speakers worldwide. Jared Diamond $(1992)^{8}$ even suggests that 'it may be somehow more initially 'obvious' to human psychology" because it is the most common order developed in Creole and pidgin languages.

In this study, we will test these sequences on lay-participants in order to attest to their usability and confirm or infirm our hypothesis on human comprehension in general, before we proceed to testing them on the real end users.

We constructed a psycholinguistic behavioral experiment protocol by adding a sentence structure to the different categories of information in our corpus. For example, imperative statements will not have an explicit $\mathrm{S}-\mathrm{V}-\mathrm{O}$ construction, but rather an implicit one: "Activate track 1" instead of "(You) activate track one." Because of the way imperative sentences are constructed in English, the subject is understood to be the person this command is addressed to without explicitly naming the subject. The sentence remains an $\mathrm{S}-\mathrm{V}-\mathrm{O}$ construct.

The study will test two independent variables: reaction time and accuracy of comprehension of the S-V-O sentential constructs vs. the coded CL constructs of the corpus in the different categories of information (action, information, title, etc.).

We will pre-test the participants for individual text comprehension of English. We will also be pre-testing our sequences for syntactic complexity by using sentence length in order to control the difficulty of the stimuli. According to Szmrecsanyi

8 Diamond, J. (1992). The third chimpanzee. New York, NY: HarperCollins. 
(2004)[13], sentence length (or a version of the Flesch-Kincaid tests) are as good a means of testing syntactic text complexity as counting syntactic nodes in a sentence. Szmrecsanyi [13] reports comparing three methods of measuring syntactic complexity: node counts, word counts, and 'Index of Syntactic Complexity'. She concludes that the three measures are near perfect proxies and can be used interchangeably. Therefore, we can feel safe to use the measure that is most economical to conduct to be able to evaluate the syntactic difficulty of our stimuli.

\section{The first results of the experiment will be exposed in the CNL workshop in July.}

\section{References}

1. Chervak, S. (1996). The Effects of Simplified English on the Performance of a Maintenance Procedure. Master's Thesis. State University of New York.

2. Chervak, S., Drury, C. and Ouellette, J. (1996). Simplified English for Aircraft Workcards.Proceedings of the Human Factors and Ergonomics Society Annual Meeting, 40(5), pp.303-307.

3. DuBay, W. (2004) Principles of Readability.

4. Eckert, D. (1997). The Use of Simplified English to Improve Task Comprehension For nonnative English Speaking aviation maintenance technician students. Doctoral Dissertation, West Virginia University, WV.

5. Hart, S., Simpson, C (1976) Effects of Linguistic Redundancy On Synthesized Cockpit Warning Message Comprehension and Concurrent Time Estimation, pp. 309-321.

6. Kiwan, D. (2000). The Effects of Time-Induced Stress On Making Inferences in Text Comprehension.

7. Kuhn, T. (2014). A Survey and Classification of Controlled Natural Languages. Computational Linguistics, 40(1), pp.121-170.

8. McNamara, D., Louwerse, M., McCarthy, P., C Graesser, C., (2010) Coh-Metrix: Capturing Linguistic Features of Cohesion, Discourse Processes, 47:4, pp. 292-330.

9. Shubert, K. Jan H. Spyridakis, Heat, S. (1995). The Comprehensibility of Simplified English in Procedures. Journal of Technical Writing and Communication, 25(4), pp. 347-369.

10. Simpson, C. A. (1976) Effects of Linguistic Redundancy on pilot's Comprehension of Synthesized Speech, pp. 294-308.

11. Simpson, G., Peterson, Robert R. Casteel, Mark, Burgess, Curt (1989). Lexical and sentence context effects in word recognition.

12. Stewart, K. (1998). Effect of AECMA Simplified English On the Comprehension of Aircraft Maintenance Procedures By Non-native English Speakers, University of British Columbia.

13. Szmrecsanyi, B (2004). On operationalizing Syntactic Complexity.

14. Temnikova, Irina. (2012). Text Complexity and Text Simplification in the Crisis Management Domain. Ph.D. thesis, University of Wolverhampton.

15. Van Oosten, P., Tanghe, D., Hoste, V (2010). Towards an Improved Methodology for Automated Readability Prediction. 